\title{
Impact of Socioeconomic Status on Lipid Profile in Type 2 Diabetic Patients: An Observational Study
}

\author{
Dalia Biswas', Prerna Agarwal'2, Mousumi Debnath ${ }^{3}$ \\ ${ }^{1}$ Prof \& Head, Dept of Physiology, JNMC, Wardha, ${ }^{2}$ Asst. Prof, Dept of Physiology, JNMC, Wardha, ${ }^{3}$ Asst. Prof. \\ Department of Neurosciences, Dr. G.D. Pol Foundation, YMT, college of Physiotherapy, Khar Ghar, Navi Mumbai
}

\begin{abstract}
Introduction: Socioeconomic status, whether assessed by income, education, or occupation, is linked to a wide range of health problems, including low birthweight, cardiovascular disease, hypertension, arthritis, diabetes, and cancer.

Method: This wasa observational study. 62 patients were included in the study group of research study. The key outcome measures were BMI, Blood Glucose Fasting \& Postmeal and total lipid profile.

Result: In our study we evaluated the lipid profile in relation to socio-economic status and found that low socioeconomic status(SES) affects the most, followed by middle SES and lastly the least affection is of higher SES.
\end{abstract}

Conclusion: Our data showed that higher income and higher education inversely affects lipid profile in diabetic patients.

Keywords: Socioeconomic status, Lipid profile, Type 2 Diabetic patients.

\section{Introduction}

Type II diabetes is a non communicable disease and a potent risk factor for cardiovascular disease (CVD). In fact, the main risk factor for an acute coronary event is dyslipidemia, as high serum levels of cholesterol are the main factor. ${ }^{1,2}$

Socioeconomic status has traditionally been defined by education, income, and occupation ${ }^{3}$.Socioeconomic status, whether assessed by income, education, or occupation, is linked to a wide range of health problems, including low birthweight, cardiovascular disease, hypertension, arthritis, diabetes, and cancer ${ }^{4}$.

Epidemiologic studies already have shown that there is health inequality in the general population with differing SES; a low educational level or low income

\section{Corresponding Author:}

Dr. Dalia Biswas

Prof \& Head, Dept of Physiology, JNMC, Wardha gives rise to higher incidence rates of various diseases and a higher risk of mortality ${ }^{5,6}$.

Dyslipidemia, as with other complex multifactorial diseases, emerges from the interaction of a genetic background with environmental and socio-economic factors. Despite the biological determinants, important epidemiological studies have shown that some social predictors, such as socio-economic stratum and education level, are also associated with changes in the lipid profile and thus influence the development of CVDs. In developed countries, cholesterol levels decrease with the progression to higher socio-economic or education levels, mainly in women. ${ }^{1,7}$.

Thus we aimed to investigate the association between blood levels of total cholesterol, high-density lipoprotein cholesterol (HDL-c), low-density lipoprotein cholesterol (LDL-c) very low density lipoprotein (VLDL) and triglycerides (TG) with the different socioeconomic and educational strata in the type 2 diabetic patients who are not on lipid-lowering medications. 


\section{Method}

This wasa observational study. 62 patients were included in the research study. The guidelines of the National Diabetes Data Group and the third set of the Adult Treatment Panel of the National Cholesterol Education Program (NCEP ATP III) was used to recruit patients with type 2 diabetes and dyslipidemia.

\section{Inclusion Criteria:}

1. Diagnosis of impaired glucose intolerance based on criteria adopted by the WHO in 1985, which was a fasting plasma glucose concentration of $140 \mathrm{mg} /$ $\mathrm{dl}$ or higher or a plasma glucose concentration of $200 \mathrm{mg} / \mathrm{dl}$ or higher two hours after an oral glucose challenge.

2. 15-70 yrs of age .

\section{Exclusion Criteria:}

1. History of Psychological problems likely to interfere with participation.

2. Chronic disease that would likely to limit the ability to continue with the study for 6 months

3. Thyroid or Liver disease

4. Physical disabilities deemed likely to interfere with participation in the study.

5. Patients who did not give consent to the study.

The patient underwent a clinical assessment, which included history (a questionnaire) and clinical examination. The variables of questionnaire were age, sex, marital status, personal history (occupation, education, socio-economic status) eating pattern, nutritional status, exercise history, smoking status and family history (including family history of diabetes)

Outcome Measures: Baseline anthropometric measurement like height and weight were taken at recruitment. Body Mass Index or BMI was calculated using the formula- weight in $\mathrm{kg}$ divided by height in meter square .

Blood Glucose was measured using a Glucometer namely BG03-Dr Morepen, Gluco one Blood Glucose monitoring system.

The fasting blood samples was analyzed for triglycerides (TG), total cholesterol (TC) and highdensity lipoprotein-cholesterol (HDL-C). Total cholesterol was estimated by Enzyme end point method. HDL cholesterol was assessed by enzyme direct method. Triglyceride by GPO-PAP method. LDL cholesterol and VLDL werel not separately estimated but calculated. LDL was calculated using the formula: LDL cholesterol $=$ Total cholesterol $-[$ HDL cholesterol + TG/5).

Socioeconomic status(SES) was divided into 3 groups namely Low, Middle and High.

SES Low- Having yearly income less than Rs 50,000 per year and education is pre-secondary.

SES Middle- Having yearly income between Rs 1.5 lacs to Rs 2 lacs per year and education is highersecondary and above.

SES High- Having yearly income more than Rs 4 lacs per year and education is post graduate and above.

The key outcome measures were BMI, Blood Glucose Fasting and total lipid profile.

Program Evaluation \& Statistical Analysis: Statistical analysis was done using descriptive, inferential and corelation statistics.

The software used in the analysis were SPSS 17.0 and Graph Pad 5.0 version and $\mathrm{p}<0.05$ was considered as level of significance.

\section{Observation:}

Table 1: Distribution of patients according to demographic characteristics.

\begin{tabular}{|l|c|c|c|}
\hline Demographic Characteristics & Mean & SD & Range \\
\hline Age (yrs) & 55.52 & 14.92 & $16-82$ \\
\hline Gender & $48 / 15$ & & $1.50-1.80$ \\
\hline Ht (meter) & 1.66 & 0.10 & $59-80$ \\
\hline Wt $(\mathrm{Kg})$ & 71.47 & 7.38 & \\
\hline
\end{tabular}


Table 2: Distribution of patients in three groups according to socio-economic status

\begin{tabular}{|c|c|c|c|}
\hline SES & Income & Education & $\chi^{2}$-value \\
\hline Low & $48(77.41 \%)$ & $45(72.58 \%)$ & \multirow{4}{*}{$\begin{array}{c}0.29 \\
\mathrm{p}=0.86, \mathrm{NS}\end{array}$} \\
\hline Middle & $10(16.12 \%)$ & $11(17.74 \%)$ & \\
\hline High & $4(6.45 \%)$ & $6(9.67 \%)$ & \\
\hline Total & $62(100 \%)$ & $62(100 \%)$ & \\
\hline
\end{tabular}

Table 3: Parameters with their mean values.

\begin{tabular}{|c|c|c|c|c|}
\hline Parameters & Mean & $\mathbf{N}$ & Std. Deviation & Std. Error Mean \\
\hline BMI & 26.33 & 63 & 3.26 & 0.41 \\
\hline FBS & 227.76 & 63 & 42.460 & 5.35 \\
\hline $\mathrm{TC}$ & 237.71 & 63 & 20.30 & 2.55 \\
\hline TG & 155.17 & 63 & 12.37 & 1.55 \\
\hline HDL & 43.71 & 63 & 8.03 & 1.01 \\
\hline LDL & 150.71 & 63 & 21.98 & 2.76 \\
\hline VLDL & 43.28 & 63 & 6.89 & 0.86 \\
\hline
\end{tabular}

Table 4: Correlation of SES with lipid profile .

\begin{tabular}{|l|c|c|c|c|}
\hline SES & TC & TG & HDL & LDL \\
\hline Low & $234 \pm 20.28$ & $155.12 \pm 12.32$ & $43.67 \pm 7.03$ & $156 \pm 23.92$ \\
\hline Middle & $228 \pm 20.22$ & $145.12 \pm 11.32$ & $55.67 \pm 8.03$ & $146 \pm 20.82$ \\
\hline High & $210 \pm 20.10$ & $138.12 \pm 12.12$ & $73.67 \pm 7.05$ & $130 \pm 21.72$ \\
\hline
\end{tabular}

Table 5: Correlation between Low, middle \& high SES and lipidprofile

\begin{tabular}{|l|c|c|c|c|}
\hline SES Low & TC & TG & HDL & LDL \\
\hline Correlation 'r' & 0.023 & 0.774 & 0.767 & 0.989 \\
\hline p-value & $0.857 \mathrm{NS}$ & $0.0001, \mathrm{~S}$ & $0.0001, \mathrm{~S}$ & $0.0001 \mathrm{~S}$. \\
\hline SES Middle & 0.028 & 0.654 & 0.868 & 0.889 \\
\hline Correlation 'r' & $0.857 \mathrm{NS}$ & $0.852, \mathrm{NS}$ & $0.0001, \mathrm{~S}$ & $0.0001 \mathrm{~S}$. \\
\hline p-value & \multicolumn{5}{|c|}{0.016} & 0.989 \\
\hline SES High & 0.019 & 0.574 & $0.845, \mathrm{NS}$ & $0.0001 \mathrm{~S}$. \\
\hline Correlation 'r' & $0.857 \mathrm{NS}$ & $0.658, \mathrm{NS}$ & \\
\hline p-value &
\end{tabular}

\section{Result}

Table 1 display anthropometric variables. Table 2 shows the distribution of patients as per SES strata. Maximum patients were in the low SES group.

Table 3 finding shows that BMI, FBS, TC, TG, HDL, LDL, VLDL were on the higher side. HDL finding was low.
Table 4 finding shows that value of TC, TG, HDL \& LDL was more for low SES as compared to other groups.

Table 5 depicts correlation of low SES with TG, HDL \& LDL, corelation of middle SES with HDL \& LDL and correlation of high SES with LDL value only. 


\section{Discussion}

In our study we evaluated the lipid profile in relation to socio-economic status and found that low SES affects the most, followed by middle SES and lastly the least affection is of higher SES. This indicates that higher income and higher education inversely affects lipid profile in diabetic patients.

Dyslipidemia is a complex disorder influenced by several factors related to genetic background and multiple environmental factors ${ }^{8}$. Dyslipidemia is associated with inadequate nutrition and low levels of physical activity, but also socio-economic disparities. This relationship was explained by McCurley et $\mathrm{al}^{9}$. who showed that people of a higher socio-economic status have a reduced risk of dyslipidemia through the mediation action of psychosocial factors (e.g. anxiety, depression and social support).

Sun GZ et al in their study observed a significant positive association between socio-economic status and dyslipidemia, in which total cholesterol and LDL-c were increased in both men and women in the higher socioeconomic strata, even after controlling for confounders. Also, higher socio-economic status was associated with an increased prevalence of hypercholesterolemia, regardless of sex. Our data corroborates a previous report by Sun et $\mathrm{al}^{10}$ in which dyslipidemia was positively associated with socio-economic status in China. Also, dyslipidemia was more prevalent in individuals of higher socio-economic status in urban regions of India ${ }^{11}$.

A possible explanation for this positive association between dyslipidemia and socio-economic status lies in the fact that social improvement facilitates easy access to some attractive unhealthy behaviors (fast food-based diet, physical inactivity, and alcohol and tobacco use $)^{12}$.

Luçandra $\mathrm{R}$ et al studied the associations between lipid profile and socio-economic status and they found difference between men and women. They observed that HDL-c and TG levels increased in women from the lower to the higher socio-economic strata, while in men they remained steady throughout the socio-economic categories. These sex differences in the association between socio-economic status and dyslipidemia, they say have been reported by other authors also.. Using data from the European Prospective Investigation of Cancer (EPIC) - Norfolk Study, Shohaimi et al. ${ }^{1}$ showed that the association between lipid levels and socio-economic indicators were more evident in women than in men. The authors showed that women in lower socio-economic strata had higher levels of LDL-c and TG. Corroborating the sex differences reported by Shohaimi et al ${ }^{1}$ study conducted in South Korea showed a prevalence of dyslipidemia of $46.8 \%$ in men and $31 \%$ in women.

Polychronopoulou A et al found in their study that young adults with higher education levels had higher levels of total cholesterol and TG than those with lower education levels ${ }^{13}$. In a rural region of China, a general inverse association was reported between education level and dyslipidemia ${ }^{10}$. Similar data were observed with Greek adolescents ${ }^{14}$. Also, evaluating the Greek participants of the EPIC Study, Benetou et al observed that total blood cholesterol was inversely related to education level in both men and women. Our results partially agree with Benetou et al.'s report, that the higher the education level, the lower the total cholesterol, HDL-c and TG .

Nam et a $1{ }^{15}$ found different results when dyslipidemia was associated with socio-economic status or education level. In contrast with the socio-economic levels assessed by the score-based questionnaires, education levels per se were not associated with any of the blood lipids tested in fully adjusted regression model in men, but a higher education level was related to lower total cholesterol and LDL-c in women. These results were the opposite when socio-economic status was used.

Himanshu M Rana et al conducted a study in which the diabetic patients presented to a tertiary care hospital in Gujrat belonging to both genders and were from lower socioeconomic strata plus having limited education in their geriatric age group. They found that there is high proportion of obesity, diabetes and hypertension among them ${ }^{16}$.

.Timothy $\mathrm{C}$ et al in their large cohort study found that advanced education and increasing income were both inversely associated with incident diabetes. This relationship was largely explained by behavioral factors, particularly body mass index ${ }^{17}$.

Maty et al. found that study participants with $<12$ years education had $50 \%$ excess risk of incident diabetes compared with those with more education $(\mathrm{HR}=1.5$; 95\%CI 1.11-2.04) ${ }^{18}$.

House JS et al in their analysis revealed that the relationship between education and diabetes was most affected by behavioral factors. BMI explained the 
majority of the SES- DM association explaining 32\% of the education and $39 \%$ of the income effects respectively. Indeed, lower educational and financial resources are in part associated with more risky health behaviors, lower levels of social support and more adverse physical and environmental exposures ${ }^{19}$.

\section{Conclusion}

Our data showed that higher income and higher education inversely affects lipid profile in type 2 diabetic patients. So stress should be given to improve education of masses at appropriate levels. This will help them in better coping from the disease. Efforts should also be made for increasing employment levels as a govt .policy.

\section{Conflict of Interest: Nil.}

\section{Source of Funding: Self.}

Ethical Clearance: Obtained from Institutional Ethical Committee before start of study.

\section{References}

1. Shohaimi S Boekholdt MS, Luben R, et al. Distribution of lipid parameters according to different socio-economic indicators - the EPICNorfolk prospective population study. BMC Public Health.2014;14:782.

2. Castelli WP, Garrison RJ Wilson PW, et al. Incidence of coronary heart disease and lipoprotein cholesterol levels. The Framingham Study. JAMA.. 1986;256 (20):2835-8

3. Katherine Newmanand. Nancy E. Adler. Socioeconomic Disparities In Health: Pathways And Policies. Health Affairsvol. 21, no. 2: The Determinants of Health.

4. E. Pamuk et al. Socioeconomic Status and Health Chartbook: Health, United States, 1998 (Hyattsville, Md.: National Center for Health Statistics, 1998).

5. Wilkinson RG, Pickett KE. Income inequality and population health: a review and explanation of the evidence. Soc Sci Med (1982) 2006; 62:1768-1784.

6. Demakakos P, Biddulph JP, Bobak M, et al Wealth and mortality at older ages: a prospective cohort study. J Epidemiol Community Health 2016; 70:346-353.

7. Benetou V, Chloptsios Y, Zavitsanos X, et al. Total cholesterol and HDL-cholesterol in relation to socio-economic status in a sample of 11, 645 Greek adults: the EPIC study in Greece. Scand J Public Health. 2000, 28(4):260-.5.

8. Ruixing Y, JinzhenW, Weixiong L, Yuming C, Dezhai Y, Shangling P. The environmental and geneticevidencefortheassociationofhyperlipidemia and hypertension. J Hypertens.2009;27 (2):251-8.

9. McCurley JL, Penedo F, Roesch SC, et al. Psychosocial factors in the relationship between socio-economic status and cardiometabolic risk: the HCHS/SOL Sociocultural Ancillary Study. Ann Behav Med.2017;51(4):477-88.

10. Sun GZ, Li Z, Guo L, et al. High prevalence of dyslipidemia and associated risk factors among rural Chinese adults. . Lipids Health Dis. 2014;13:189.

11. Guptha S, Gupta R, Deedwania P, et al. Cholesterol lipoproteins and prevalence of dyslipidemias in urban Asian Indians: a cross sectional study. Indian Heart J. 2014;66(3):280-8.

12. Luçandra R Espírito Santo, Thaís O Faria, Carla Silvana O Silva, Lorena A Xavier, Vivianne C Reis, Gabriel A Mota, Marise F Silveira, José Geraldo Mill, Marcelo P Baldo. Socioeconomic status and education level are associated with dyslipidemia in adults not taking lipid-lowering medication: a population-based study. International Health, 2019. ihz089, https://doi.org/10.1093/inthealth/ihz089.

13. Polychronopoulou A, Georgiadis E, Kalandidi A, et al. Serum cholesterol, triglycerides and phospholipids, and $\mathrm{ABO}$ and rhesus (Rh0D) antigen among young Greeks. Hum Biol. 1977; 49(4):605-10.

14. Petridou E, Kouri N, Trichopoulos D, et al. School injuries in Athens: socio-economic and family risk factors. J Epidemiol Community Health. 1994;48(5):490-1.

15. Nam GE, Cho KH, Park YG, et al. Socio-economic status and dyslipidemia in Korean adults: the 2008-2010 Korea National Health and Nutrition Examination Survey. Prev Med. 2013, 57, (4): 304-9.

16. Himanshu M Rana, Parag Chavda, Chirag C Rathod, Meera Mavani. Socio-demographic and anthropometric profile of diabetic patients attending diabetes clinic in tertiary care hospital of central Gujarat . National journal of community medicine. 2015; 6(4).

17. Timothy C. Lee, Robert J. Glynn, Jessica M. Peña, Nina P. Paynter, David Conen, Paul M. Ridker, 
Aruna D. Pradhan, Julie E. Buring, Michelle A. Albert Lee TC, Glynn RJ, Peña JM, Paynter NP, Conen D, Ridker PM, et al. Socioeconomic Status and Incident Type 2 Diabetes Mellitus: Data from the Women's Health Study.2011; PLoS ONE 6(12): e27670. https://doi.org/10.1371/journal. pone.0027670)

18. Maty SC, Everson-Rose SA, Haan MN,
Raghunathan TE, Kaplan GA (2005) Education, income, occupation, and the 34-year incidence (1965-99) of Type 2 diabetes in the Alameda County Study. Int J Epidemiol 34(6): 1274-1281.

19. House JS, Williams DR . Psychosocial Pathways Linking SES and CVD. In National Institutes of Health, National Heart, Lung, and Blood Institute's Report of the Conference on Socioeconomic Status and Cardiovascular Health and Disease1996. 